\title{
Humor e melancolia: montagem poética - uma entrevista com o poeta brasileiro Francisco Alvim
}

\section{Humor and melancholy: poetic montage - an interview with the Brazilian poet Francisco Alvim}

Deyse Moreira ${ }^{1}$

\section{Resumo:}

Francisco Alvim (1938 -), poeta brasileiro contemporâneo, estreou em 1968 com o livro Sol dos Cegos. Na entrevista que segue, Francisco Alvim relata sua trajetória e influências literárias, comenta a concepção de alguns livros e poemas, tecendo reflexões sobre a linguagem poética no geral e sua própria escrita, próxima de recursos como a montagem e a teatralidade. Movendo-se entre o evidente e o encoberto, entre o humor e a melancolia, o cenário fragmentário de seus poemas desloca nosso olhar, desentranhando cenas de desajuste e de mal-estar por detrás do riso e das expressões feitas.

Palavras-chave: Francisco Alvim. Poesia contemporânea brasileira. Entrevista.

\begin{abstract}
:
Francisco Alvim (1938 -), contemporary Bazilian poet, debuted in 1968 with the book Sol dos Cegos. In the interview that follows, Francisco Alvim reports his trajectory and literary influences, comments on the conception of some books and poems, weaving reflections on poetic language in general and his own writing, close to resources such as montage and theatricality. Moving between the evident and the hidden, humor and melancholy, the fragmentary scenery of his poems displaces our gaze, unravelling scenes of maladjustment and
\end{abstract}

1 Doutoranda em Estudos Lusófonos pela Sorbonne Université, sob a orientação do professor Michel Riaudel (Sorbonne Université), codireção da professora Sandra Teixeira (Université de Poitiers) e cotutela da professora Ida Alves (Universidade Federal Fluminense). 
malaise behind the laughter and trite expressions.

Keywords: Francisco Alvim. Contemporary Brazilian poetry. Interview.

Francisco Alvim nasceu em Araxá, Minas Gerais, em 1938. Publicou seu primeiro livro de poemas, Sol dos Cegos, em 1968. Foi diplomata, atuando na embaixada do Brasil na França entre 1969 e 1971. Ao retornar ao Brasil, em 1971, ainda no período da ditadura militar, instalou-se no Rio de Janeiro, aproximando-se dos escritores que ficaram conhecidos como poetas marginais. Conheceu Cacaso que o convidou a participar da coleção de poesia Frenesi, na qual publicou, em 1974, o livro Passatempo. A produção coletiva e independente de poesia tornou-se uma alternativa na década de 70 diante do contexto político de autoritarismo. Este modo de produção literária, ao deslocar os meios de circulação, marcou a "marginalidade" das obras poéticas dessa geração como uma forma de resistência cultural, de recusa a se paralisar e a silenciar.

Francisco Alvim, diplomata, recém-chegado de "fora" do país, mas "dentro" das instituições brasileiras, passa a pertencer também ao lado "marginal" de um movimento literário antissistema, que marca a recepção de sua obra até hoje. Esse limiar, estar "entre", rompe os limites de uma dimensão de "fora" e de "dentro", o que pode ser percebido na referencialidade embaralhada de seus poemas e na composição poética aberta: sua obra é palco onde se espalham os entrechos, traduzindo uma subjetividade permeada de vozes outras.

Em 1975, Francisco Alvim participou do registro da "produção em curso de vinte poetas do Rio de Janeiro", selecionados por Eudoro Augusto e Bernardo Vilhena, numa contribuição à Revista Malasartes, intitulada Consciência marginal. Francisco Alvim também participou da antologia 26 poetas hoje, organizada por Heloísa Buarque de Hollanda e publicada em 1976 pela editora espanhola Labor. Em 1978, publicou Dia sim dia não, também de modo independente e em parceria com Eudoro 
Augusto.

No ano de 1981, Francisco Alvim lançou os livros Festa e Lago, Montanha, publicados na coleção Capricho. Ademais, nesse mesmo ano, foi publicada a primeira reunião de sua obra poética, Passatempo e outros poemas, na coleção Cantadas Literárias, pela editora Brasiliense. $\mathrm{O}$ único livro que não foi incluído na coletânea foi Dia sim Dia não. Portanto, até 1981, seus livros foram lançados em edições artesanais, inserindo-se no circuito comercial das grandes editoras a partir da publicação dessa coletânea, a qual recebeu o Prêmio Jabuti em 1982. Desde então, sua obra poética passou a ser mais conhecida. Em 1982, Francisco Alvim também começou a escrever artigos e crônicas para a grande imprensa, sobretudo à Folha de S. Paulo.

Em 1988, como marco de 20 anos de sua obra poética, Francisco Alvim publicou $O$ corpo fora, incluído na coletânea Poesias Reunidas, 1968-1988, lançado na coleção Claro Enigma, pela editora Livraria Duas Cidades. A coletânea recebeu o Prêmio Jabuti em 1989. São 12 anos que separam os livros O corpo Fora e Elefante, publicado em 2000 pela editora Companhia das Letras. Neste intervalo, Francisco Alvim exerceu o cargo de cônsul-geral do Brasil em Barcelona, de 1995 a 1999, em seguida, em Roterdã, de 1999 a 2003.

No ano de 2004, a editora CosacNaify, em parceria com a editora 7Letras, reuniu toda a obra poética de Francisco Alvim até então, lançando Poemas [1968-2000] na Coleção Ás de Colete. Passados 11 anos da publicação de Elefante, o poeta lançou seu livro de poesia mais recente, Metro nenhum, publicado em 2011, também pela Companhia das Letras. No intervalo entre esses dois últimos livros, Francisco Alvim foi nomeado embaixador do Brasil na Costa Rica, em 2003, aposentando-se do Ministério das Relações Internacionais em 2008. Em 2018, na ocasião da comemoração dos 80 anos do poeta, a revista Suplemento Pernambuco organizou uma edição especial em sua homenagem. Também foi publicada 
a antologia Francisco Alvim 80 anos, como parte do "Ciclo Vozes, Versos", organizado por Heitor Ferraz e Tarso de Melo.

A entrevista que segue foi realizada em junho de 2018, na casa do poeta, em Brasília. Nela, Francisco Alvim relata sua trajetória e influências literárias, comenta a concepção de alguns livros e poemas, tecendo reflexões sobre a linguagem poética no geral e sua própria escrita, próxima de recursos como a montagem e a teatralidade. Movendo-se entre o evidente e o encoberto, entre o humor e a melancolia, o cenário fragmentário de seus poemas desloca nosso olhar, desentranhando cenas de desajuste e de mal-estar por detrás do riso e das expressões feitas. Diante disso, o leitor é convidado a articular as fissuras, os entrechos, as diferentes camadas da linguagem, como se a montagem pudesse lançar outras luzes às cenas, ao mundo, desenhando contornos que ainda não tiveram lugar.

Deyse dos Santos Moreira: Sua poesia estimula uma reflexão sobre a identidade brasileira, sobre a nossa cultura, nossas contradições, nossos vícios e preconceitos. Vários poemas expõem a prática do "jeitinho" brasileiro, descortinando um complexo espectro social do Brasil. A esse respeito, você poderia comentar a dimensão social em sua poesia?

Francisco Alvim: A minha tentativa será de considerá-la um ângulo mais contemplativo, mais visual do que outra coisa qualquer. Eu acho que esse dado social vem sempre porque ele nos circunda. Desde muito menino, os aspectos propriamente da vida brasileira me tomaram e eu tenho uma tendência a ser mais contemplativo, me vejo como uma pessoa afeiçoada a janelas. Eu gosto de uma janela. Adorava as janelas holandesas porque elas atravessavam a casa, em geral quadradas. $\mathrm{Na}$ face da rua, eles fazem um janelão e, depois, no fundo da casa, tem outro janelão enorme, então, a luz entra por todos os lados. As casas holandesas nisso diferem um pouco das francesas que são mais escuras, uma arquitetura mais fechada. Sempre que você vê uma casa francesa, você pensa em 
tapetes, cortinados, guéridons, coisas assim. A holandesa é mais aberta. Eles têm uma relação com a luz muito forte. Aliás, na pintura deles, você vê isso. Então, esse aspecto social entra, quer dizer, o Brasil é um país aberto, um país luminoso, é um país que você tem vontade de sair de casa, não te previne. Na Europa, você tem o frio, os espaços são mais ou menos isolados. No Brasil, há um convite permanente para sair, o interior das casas e o exterior pouco diferem. Então, esse contato com a vida visual e de entrechos, quer dizer, a conversa, o som que vem e entra por todos os lados. As histórias são de uma riqueza extraordinária, se você presta atenção... Isso em qualquer parte do mundo, em qualquer lugar, qualquer situação. $\mathrm{O}$ homem, tendo a oportunidade de bater um papo, ele bate. E, naquele papo, vem uma quantidade de informações e de histórias... Aí entra a narrativa. Eu sou um narrador frustrado, adoro os entrechos, adoro as histórias, as anedotas. O país tem muito que ver e que dizer, e, desde menino, eu fui muito ligado a isso.

D.S.M.: Você estreia como poeta com o livro Sol de Cegos, em 1968. No ano seguinte, em 1969, você passa a viver em Paris até 1971, onde atuou como secretário da representação do Brasil na Unesco. Poderia falar um pouco da influência dessa estadia na França em sua escrita poética?

F.A.: Todo mundo acha que poeta é uma coisa a vida inteira e toda a hora. E não é. O Drummond mesmo dizia: "eu não sou poeta permanentemente". Quando você quer ser poeta, se tem essa ambição, você vai ler e vai fazer a coisa numa pauta, uma pauta musical, como se fosse uma música. Você vai aprendendo as notas de um, de outro, uns já falecidos, outros ainda vivos. Sempre gosto de pensar nesses vivos como passarinhos. A poesia feita por passarinhos. Você ouve o tom de um sujeito que está aqui ao lado, vivendo as mesmas coisas, da mesma geração. Você ouve o tom e vai no pio dele, ele vai te dar uma nota qualquer. Você continua aquele canto que vem dele, e aquilo vai passando e vai se armando um coro de passarinhos. E tem os velhos, tem os poetas de sempre e a França 
é rica desses, sobretudo. Eu tive muita leitura. Muito antes de ir para a França, eu lia os franceses, eu lia os clássicos, Baudelaire, Rimbaud... Tudo naquela fase que inaugura os tempos da poesia atual. Os tempos modernos vêm com os franceses, vem com Baudelaire que é o grande iniciador. A poesia de Baudelaire é uma coisa extraordinária, porque ele rompe, mas ainda dentro; então,você vê a ressonância do romantismo todo que é onde começa a grande modernidade. Aí vem mais dos alemães que dos franceses, a primeira geração romântica, poetas notáveis como Novalis, Goethe... Aí começa a surgir a sensibilidade moderna. E Baudelaire traz muito desse mundo com Hugo, as assonâncias que ele tem com Hugo, mas começa a operar as dissonâncias. A poesia rompe com fronteiras que é sempre o papel da linguagem poética - ela está na frente, e ela não perdeu isso. Dizem que a imagem vale mais do que mil palavras - não é muito verdade, porque a poesia está sempre atenta. Então, essa ruptura no nível da linguagem, a poesia está operando, é uma grande ambição dela. Quando ela consegue, ela bouleverse, ela rompe as barreiras de todas as linguagens, aí todas vão atrás dela. Esse poder da linguagem poética é uma coisa extraordinária, é uma coisa de uma inventividade, ela está constantemente na fronteira. E aí entram coisas de uma complexidade incrível. Os filósofos, vira e mexe, estão metidos com poetas. É uma experiência vertiginosa. Uma experiência de conhecimento muito intensa. A minha ligação com os franceses é enorme, esse pessoal todo eu adorava e os outros, Corbière, Lautréamont... é uma coisa infinita. Esses homens fazem parte do meu sangue, da minha percepção das coisas e eles vão vindo até chegar num Drummond, nas pessoas que me são caras e que fazem parte da minha estrutura mental e de sensibilidade. Drummond, Bandeira, Jorge de Lima...

D.S.M.: O livro Passatempo, de 1974, apresenta fotogramas de uma escultura em diferentes ângulos, cujo contraste entre luz e sombra/ claro e escuro se destaca. Você poderia comentar esses fotogramas e a 
tópica da luz nos poemas? Tendo em conta o primeiro poema intitulado Luz e a epígrafe "Eu sou ninguém; meu nome é ninguém/ Toda coisa que existe é uma luz".

F.A.: Esse livro, Passatempo, ele foi muito importante para mim, por isso eu fiz questão de pôr uma nota no final indicando que parte dele foi escrita em Paris e outra parte em minha volta ao Rio. Ele tem dois tempos, tem o tempo do passatempo, que é ele todo, e a parte relativa ao Rio, a partir de 71 a 73/74. São poucos poemas. O livro é fino e tem esse título de Exemplar Proceder. Então, é um livro que, de certa maneira, eu senti que ali a minha voz estava se constituindo, mais do que no Sol de Cegos que é mais um aprendizado. Estou escrevendo nesta grande pauta da tradição e das influências dos nossos grandes, daquela geração que é a idade de ouro nossa, da nossa literatura modernista, o Drummond, o Cabral, o Jorge de Lima, os grandes poetas do período, o Bandeira, o Murilo, todos poetas gigantescos. Então, Passatempo traz um pouco aquela seivinha nova naquele período incrível que é a vida da gente na década dos 30 anos, eu estava entrando nela. Tudo tem um senso, um vício, um frescor e, ao mesmo tempo, a força da inteligência, da sensibilidade orgânica das coisas. O corpo reage de uma maneira, parece um universo luminoso, ele recebe tudo com graça. O Passatempo, acho que comecei porque fiquei muito amigo do Cacaso e estava vivendo muito aquele ambiente dos anos 70 no Rio, que coincide com esses poemas que estão boa parte sendo feito no Brasil, e outros que trouxe de Paris. Aí o Cacaso, que era uma figura notável com espírito empreendedor, logo teve a ideia magnífica de fazer uma coleção. Então, surgem estes livros, entre os quais o Passatempo. O Cacaso era gregário, ele tinha essa faculdade transitiva, de entrar em contato com as pessoas, motivá-las, era uma prosa encantadora. Ele ia puxando conversa e com jeitão muito brasileiro, "sou brasileiro de estatura mediana, gosto muito de fulana, mas é sicrana que me quer..." Aquele tom da língua escrevendo sempre a favor. Como Bandeira, o grande mestre dele 
era o Bandeira. O Cabral e o Drummond escrevem a contrapelo, cheios de arestas, eles vão pegando os cactos... e o Bandeira escreve na onda, ele surfa, ele vai na linguagem e ela vira uma música sem ser música. Então, o convívio foi muito bom nessa época. O Cacaso tinha uma ideia de livro, que várias pessoas tinham que entrar e ilustravam e eu comecei a ficar com inveja, a achar que eu tinha que fazer alguma coisa semelhante, mas não achava... então eu me lembrei. Paris pra mim era uma coisa de outro mundo. Eu estava lendo Proust neste período e Paris ressoava em vários tempos, tempo de Baudelaire, tempo de Corbière, de Proust, de Lautréamont, de todos. Então, eu adorava esse lugar da estátua. Quando iam amigos, eu fazia questão de passeá-los por lugares onde eu gostava. E essa estátua, que já não está mais lá, acho que tiraram, fizeram museu, era muito frequentada por mim. Eram Les bronzes d'Aristide Maillol, ficavam todos no jardim do Trocadéro. Eu passava tardes perdidas, e eu gostava muito. Eu queria ter sido pintor por influência de minha irmã mais jovem, Maria Lúcia. Ela me fez gostar de pintura desde rapazinho. Eu ia pra lá nos finais de tarde e a luz era uma coisa divina. Essa mulher era uma gigante, que é outro tema da poesia francesa e da mulher em geral, "la géante", e essa é a maior delas. Ela recebe uma espécie de universo, como se ela fosse uma constelação perdida no cosmos, muito mais do que uma estrela, um conjunto imenso de estrelas. Ela está numa posição estranha porque é como se fosse uma posição de queda em que ela absorve o cosmo de uma potência inacreditável, uma potência feminina porque tem uma doçura, uma coisa que homem não tem. Eu ficava extasiado com essa escultura. Eu levei por lá um amigo que filmou e tive essa ideia de pôr essas fotos no livro, então, pedi ao João Carlos, cineasta, que deu um tratamento diferente, uma coisa meio mundo do Proust. O mundo do Proust eu não consegui, mas consegui um pouco do mundo anterior, que tem um pouco o mundo da guerra, de Auschwitz, e toda aquela tragédia horrorosa que Paris estava cheia. Você andava pelas ruas e tinha lá quem morreu, tinha lá um 
buraco de bala e a plaquinha de quem foi fuzilado. Enfim, a epígrafe, tinha uma coisa misteriosa na minha cabeça de que o ideal não é o eu, é você não ser realmente ninguém, quer dizer, todo esse esforço do poeta de se distinguir, desde menino que está muito ligado a uma coisa defensiva que você precisa se afirmar, dentro das contingências históricas, esse instinto de sobrevivência, de luta pela vida te põe numa posição agressiva. Então, você tem que se destacar da multidão, o horror é você se misturar. Você quer ficar por cima, isso é uma coisa que te é incutida desde muito cedo. $\mathrm{E}$ aí, essa coisa que a idade vai te dando, eu já começava a duvidar um pouco desse ego, e a vontade é ao contrário, é voltar pro rebanho e achar que a verdade está ali no rebanho que passa a ter outro sentido, não é aquele rebanho feroz, que você tem que se livrar dele, pensar por si próprio, não se confundir, a sobrevivência está assegurada pela inteligência, e a gente viu no que isso deu... esse verso prodigioso está na Odisseia, quando Odisseu entra na gruta e está lá Polifemo, o gigante com aquele olho na testa e cego. Aí o Ulisses entra, ele vai matar Polifemo, vai confrontar-se com ele. O Polifemo sente que tem alguma coisa e pergunta "quem está aí? Qual seu nome?”. Aí Ulisses responde, “eu sou ninguém”. É uma maravilha. E isso vem lá atrás... E tem essa coisa da luz, a luz me impressionava muito, a luz justamente de Paris. O verso "Toda coisa que existe é uma luz", isso é um verso que está nos cantos de Pound. O interessante dos cantos é que o Pound faz uma montagem que é outra coisa que eu peguei muito dele. Ele fragmenta e entra tudo ali, entra anedotas, entra perfis que ele faz de contemporâneos, entra doutrina econômica, entra um mundo de coisas - era um círculo extremamente culto e aquela pantomima dele. Eu não acompanhava aquilo. Ele era um homem de uma erudição, de uma formação muito mais apurada do que a minha, mas eu via o teatro que ele fazia com aquilo tudo e aquele teatro me impressionava. $\mathrm{O}$ teatro do conhecimento, quer dizer, aquele espírito equivalente a um criador do renascimento que está com o mundo todo para ser formado. Esse verso me 
impressionou muito, ele era de um espanhol... eu me esqueci, eu soube já, tenho isso anotado até, mas minha memória furou, perdeu-se... e é bom que se perca mesmo...

D.S.M.: O poema "Moça de Bicicleta" termina com os versos "(O Corpo: um sino ouvindo / e repetindo a paisagem $)$ ". Mas esse corpo que ecoa, ouve e repete a paisagem parece que também é marcado pelo impasse: falar ou não falar; ir ou ficar; ver/escutar ou não. Você acha que faz sentido essa marca do impasse?

F.A.: Nesse momento do poema, eu acho que faz, no sentido de que o impasse, de fato, existe, mas nesse momento é um estado perto da fusão, quer dizer, é a visão de que a natureza entra, tudo entra, tudo é som, de certa maneira. O sino aí é a voz de tudo isso, é um universo que é soante, ele soa, é uma sensação de epifania, mas, de fato, por trás, como uma sombra que não se vê, certamente tem essa questão do impasse, que volta em outros poemas. Tem aquela batida de porta, tem o poema que fala do jardim e, de repente, a voz volta-se pra dentro e diz que está voltando pelo escuro corredor que vai do meu corpo a minha mente, uma coisa assim. É o fora e o dentro, é uma janela, uma paisagem serena de fora, de repente, aquilo se transforma numa zona escura. O sino é fora, mas ele traz um som de harmonia, não é a porta batendo.

D.S.M.: Gostei muito de um dos comentários que nos enviou, no qual fala sobre o elefante que frequenta o livro. Cito "Anônimo e sonoro. Trombeteador (em surdina). A voz de um, a voz de todos. Cheio de ar. Vazio do si. Alheio". Poderia falar um pouco mais desse elefante que, inclusive, dá título ao livro?

F.A.: Eu vi esse elefante que era uma família de elefante. Nós estávamos, eu e Clara, na África, no Quênia. Estávamos numa reserva que eles tinham na base do Kilimanjaro, e aquela planície, aquele morro que parece um vulcão gordo, enorme que se perde nas nuvens... Quando a gente chegou, infelizmente ele estava encoberto, só se via até a 
metade, tem a parte de neves eternas que fica pra cima, mas essa a gente não chegou a ver. Mas essa montanha no meio de uma planície, de um planalto, como Brasília, sendo que lá é mais regular, mais baixo. Aquela região consegue ser ainda mais velha do que essa nossa daqui que é uma das mais velhas do mundo, inclusive porque se desprega da África. E ali, aquela beleza, aquela coisa deslumbrante, aquela montanha que começava por todos os lados, mas estava envolta duma terra muito maior. Então, chega essa família de elefantes, tinha um poço de água. Estávamos todos comendo dentro do restaurante e todo mundo saiu voando em direção aos bichos. Eram gigantes, elefantes enormes. Os garçons diziam: "Cuidado! Cuidado! São feras!”. E todos assustadíssimos porque realmente uma mãe daquelas com todos os bebezinhos podiam se assustar e investir. Mas eles eram de boa paz, ficaram bebendo água, ficaram ali à vontade, aqueles seis, sete elefantes e aquela montanha de bicho e de carne, aquela carne cinza, escura. A sensação que você tem é de que são bailarinos realmente, porque o vento entra neles, aquilo tudo tem vazios de carne que se incham de repente e viram baobás. É uma mistura de terra, de pedra, com água, com ar, e tudo isso no corpo cinza enorme, é um cosmos, uma coisa deslumbrante, um ballet, uma dança prodigiosa, um ritmo. Eu fiquei com esse elefante na cabeça. Um belo dia aqui em Brasília, eu fiquei com vontade de me lembrar de como esse poema nasce, porque ele nasce com um tom tão diferente do que eu faço e do que eu fazia, sobretudo nessa época. Eu já estava muito dominado por esse realismo das conversas e eu só consigo me lembrar disso um pouco conceitualmente porque eu penso nesse poema e ele me recorda a primeira paixão que eu tive por poesia que foi através não do Drummond, mas do Jorge de Lima. As metáforas todas que eu lutei minha vida toda para emudecê-las, essa capacidade de estabelecer analogias, própria do recurso da metáfora que você vê muito no Sol de Cegos, e vê, volta e meia, tanto no próprio elefante, mesmo depois, que ressurge, é o Jorge de Lima que está me pegando pela mão e 
me levando para esse lado. Eu que pensava que tinha dado uma rasteira nele pra ficar com o Drummond... poeta é um caso sério, quando um te pega, você está perdido, aquilo te devora, é impressionante.

D.S.M.: Dos poetas brasileiros contemporâneos com quais você se sente mais próximo? Por quê?

F.A.: Do pessoal que veio depois, mesmo quando não participava diretamente, eu acompanhei muita coisa. Eu começo a fazer poemas com meus quatorze, quinze anos, então, pego os anos 50, geração de 45 e os modernistas. Me relacionei pessoalmente com Drummond que era muito amigo de minha irmã mais velha. Eu estive com Drummond algumas vezes, depois eu comecei a namorar a Clara que é de uma família de modernistas. O pai dela é o Rodrigo Melo Franco de Andrade, que foi o diretor do patrimônio histórico. Conheci o Bandeira, conheci o Vinícius, conheci o Nava, conheci essa gente toda porque eram todos amigos fraternos. Então, isso é a tradição. Quando eu chego no Rio, em 71, nós éramos muito amigos, somos, da Heloisa Buarque de Holanda que era colega de Clara e grande amiga. Isso mesmo antes de ir para o exterior, em 68, mas a poesia estava um pouco parada nesse período. Tinha uma geração intermédia com quem eu me relacionei também, o Octávio Mora, a Lélia Coelho Frota, o Fernando Mendes Vianna, Marly de Oliveira, enfim, esse pessoal todo. Eu pegava livros de todos os lados. Um grande amigo meu era o Alexandre Eulálio que tinha uma cultura excepcional, muito jovem, era um prodígio de leitor. Tinha lido tudo, e sabia, e convivia, era um sujeito de uma energia intelectual incrível, ia atrás, batia na porta. Com vinte e poucos anos, foi à Buenos Aires, foi lá no apartamento do Borges, bateu na porta e bateram uma conversa que durou um dia, sei lá. O Borges ficou encantado com ele. Foi um dos primeiros leitores do Borges no Brasil, ele e o Fausto Cunha. O Borges, nessa época, então, era absolutamente acessível, gostava de conversar, se relacionava com as pessoas. Então, o Alexandre me fez ler o Dalton Trevisan ainda nos gibizinhos que ele produzia na Revista Joaquim 
que ele tinha lá em Curitiba que distribuía pelo correio. O Alexandre tinha na casa dele e eu lia. Oswald de Andrade, muito antes de $O$ Rei da vela ter sido descoberto por nosso caro José Celso. Então era uma fonte de conhecimento muito grande. Mas, quando eu volto, o país era outro. Houve uma diferença. Quando eu saí, era uma alegria desenfreada, uma farra festiva, em 64, 68, era uma farra tremenda, a esquerda festiva, todos os amigos, festas pra baixo e pra cima. De repente, você volta em 71 e é aquela tristeza, camburões pra todos os lados, gente desaparecendo... Por outro lado, uma efervescência misteriosíssima porque saía nas universidades. Nessa época, eu saí do Itamaraty, fiquei fora, tirei uma licença de uns 4 anos e conheci essa turma toda porque todos estavam na PUC. Clara era professora lá, professora de Ana Cristina, amicíssima. O Cacaso se tornou um grande amigo. Tem um episódio, a criação da Frenesi. O Cacaso, como eu disse, era uma pessoa muito transitiva, ele convivia muito com o pessoal da Nuvem Cigana, pessoal jovem. Há uma diferença de idade muito grande entre mim e essa gente, uns 10 anos por aí, com uma formação muito diferente da minha.

D.S.M.: Jean Starobinski, em seu livro L'Encre de la mélancolie, aponta que uma das saídas mais sublimes do universo melancólico seria o humor, como se o humor permitisse observar a própria vida, as próprias mazelas com olhar mais distanciado, como uma reação ao sofrimento, tornando o mundo momentaneamente amigável. Você poderia comentar a relação entre o humor e a melancolia em sua poesia?

F.A.: $\mathrm{Eu}$ tenho um grande amigo que teve uma importância na minha vida muito grande, não só pela amizade que a gente teve, mas, nessa área literária, nós vivemos muitas experiências em comum, e continuamos vivendo, que é o Carlos Felipe Saldanha, o Zuca. Ele é meu professor de muitas coisas, inclusive de humor. Ele tem um humor em termos brasileiros, porque realmente tem uma coisa muito brasileira nele, mas, ao mesmo tempo, com uma formação extraordinária porque 
ele é um sujeito com um conhecimento, uma profundidade de visão, uma sensibilidade enorme. Nós vivemos situações extraordinárias, porque estudamos juntos e entramos praticamente juntos no Itamaraty e aí é que eu o conheci. Passamos muitos anos reprovados os dois, e sempre juntos. Vivemos as agruras daquela situação de ter que fazer um exame dificílimo, somos pouco dotados para aquela circunstância. As situações que a gente vivia, o dia a dia, e aquilo se refletia na literatura que a gente fazia. Eu me deliciava, a gente ria o dia inteiro, ao mesmo tempo, aquelas coisas dolorosas que se passavam a nossa volta, mas que, por conta do teatro que a gente armava, viravam coisas amigáveis, afáveis, porque o humor desarma, ele tem esse dom... Desde o humor de Chico Anysio até o Sterne do Machado, não há garrucha que resista a um olhar fino de um humor. O Felipe tinha essa capacidade inacreditável de mudar a realidade das coisas, como se você vivesse num mundo mágico, paralelo, porque as coisas eram tremendas. Você, aos 20 anos, ter que armar uma profissão, é difícil, é complicado, com o Brasil, que é sempre esse tremor de terra, você não sabe mais qual é a imaginação de pessoas muito jovens. Você vem, entra na sua casa, aquilo te impressiona. Ouve uma conversa aqui, uma conversa ali, uma quantidade de entrechos e enredos e riscos tremendos. Você vive num imaginário, num plano de imaginação solta. O mundo é um tumulto. E essas visões que nós enfrentamos bravamente eu devo muito a ele. Concordo inteiramente que a melancolia, tanto nas coisas que ele faz também, como nas que eu faço, está presente. Ele realmente é um grande humorista. Eu não me considero um humorista porque tem muita ironia nas coisas que eu faço. Eu tenho muita desconfiança da ironia, ela é uma defesa prodigiosa, ela te defende de golpes tremendos na vida, mas o humor demanda mais da imaginação. A ironia tem um vínculo com a realidade muito estreito. Você responde a coisas que estão te acontecendo de maneira muito direta, aí você se fere com aquilo, porque é uma arma que se volta muito contra quem produz, ao passo que o humor tem uma 
fabulação. O recurso da imaginação no humor é maior do que no da ironia. A ironia para ser efetiva ela tem que ter esse compromisso com a realidade, e a realidade sempre te rebaixa. Você tem que lutar um pouco nos termos dela para superá-la um pouco. A ironia é uma faca de dois gumes. Você se fere e fere o outro, e a ferida do outro, de uma maneira ou de outra, volta sobre si mesmo. Tem um verso do Drummond que eu esqueço... "Pancada na sua nuca/ na minha é que vai doer".

Recebido em: 28/05/2020

Aprovado em: 04/07/2020 